\title{
Parthenogenic Haploids in Melon: Generation and Molecular Characterization of a Doubled Haploid Line Population
}

\author{
Maria Jose Gonzalo \\ IRTA, Center for Research in Agricultural Genomics (CSIC-IRTA-UAB), Ctra. de Cabrils, Km 2, \\ E-08348 Cabrils (Barcelona), Spain; and Estación Experimental de Aula Dei-CSIC, Dept. \\ Pomología. Apdo. 13034, 50080 Zaragoza, Spain \\ Elisabet Claveria \\ IRTA, Center for Research in Agricultural Genomics (CSIC-IRTA-UAB), Ctra. de Cabrils, Km 2, \\ E-08348 Cabrils (Barcelona), Spain
}

\begin{abstract}
Antonio J. Monforte
IRTA, Center for Research in Agricultural Genomics (CSIC-IRTA-UAB), Ctra. de Cabrils, Km 2, E-08348 Cabrils (Barcelona), Spain; and Instituto de Biologia Molecular y Celular de Plantas (IBMCP), Universidad Politécnica de Valencia (UPV)-Consejo Superior de Investigaciones Científicas (CSIC), Ciudad Politécnica de la Innovación (CPI), Ed. 8E, C/Ingeniero Fausto Elio s/n, 46022 Valencia, Spain

Ramon Dolcet-Sanjuan ${ }^{1}$

IRTA, Center for Research in Agricultural Genomics (CSIC-IRTA-UAB), Ctra. de Cabrils, Km 2, E-08348 Cabrils (Barcelona), Spain
\end{abstract}

\begin{abstract}
AdDitional INDEX words. Cucurbitaceae, parthenogenesis, pure line, hybrid, DHL, markers, segregation distortion
Abstract. Melon (Cucumis melo) is one of the principal vegetable crops for fresh market, for which a large number of breeding programs, oriented to generate inbred pure lines and hybrids, is established worldwide. The process to obtain and select these lines has been highly accelerated by the use of biotechnological techniques such as the generation of doubled haploid line (DHL) populations and molecular markers. Moreover, the use of DHLs in genetic studies is a useful tool because of their complete homozygosity and the permanent availability of plant material perpetuated by seed. In this work, the parthenogenetic response of 17 melon genotypes and the $F_{1}$ hybrid PI $161375 \times$ Spanish cultivar Piel de Sapo (PS) was studied considering three stages along the in vitro DHL generation process. The response of the analyzed melon cultivars was heterogeneous through the DHL generation with different limiting steps for each genotype. The response of the PI $161375 \times$ PS hybrid was more similar to the male (PS) than the female parent (PI 161375), although the response of the maternal genotype was higher for some stages. This points to the important role of alleles from both parents in the different steps of the DHL generation process, and it could explain the identification of six genomic regions with distorted allelic segregation skewed toward PS or PI 161375. This hybrid was used to generate a population of 109 DHLs, the gametophytic origin of which was confirmed by flow cytometry and molecular markers.
\end{abstract}

Melon is a member of the Cucurbitaceae family, which includes several important crop species such as cucumber (Cucumis sativus), squash (Cucurbita maxima), zucchini (Cucurbita pepo), and watermelon (Citrullus lanatus). Melon is widely cultivated in tropical, subtropical, and temperate regions around the world, becoming one of the principal vegetable crops for fresh market. Breeding programs for this species are generally oriented to obtain inbred lines as a previous step for

\footnotetext{
Received for publication 21 June 2010. Accepted for publication 5 Jan. 2011. This work was supported in part by the Spanish seed company Semillas Fitó S.A. (Barcelona, Spain) and the research projects AGL2000-03602, AGL200309175-C02-01, and 2FD1997-0325 financed by the Spanish Ministry of Science and Innovation and with the support of the Ministry of Innovation, Universities and Enterprise of Catalonia.

We thank Dr. Jaume Comas, Serveis Científico-Tècnics, Universitat de Barcelona, for help with the flow cytometry determinations.

Use of trade names does not imply endorsement of the products named or criticism of similar ones not named.

${ }^{1}$ Corresponding author. E-mail: ramon.dolcet@irta.cat.
}

commercial hybrid production. This process can be shortened by the generation of inbred lines from doubled haploid (DH) plants. Because the complete genome of DH plants is in a homozygous state, no heterozygous genomic regions are found, and completely homozygous individuals are obtained in only one generation (Morrison and Evans, 1988). Furthermore, the incorporation of other biotechnological tools to the breeding programs such as marker-assisted selection coupled with in vitro production of $\mathrm{DH}$ lines accelerates the hybrid production process.

Haploids, derived from diploid plants, are generated from gametes of only one parent having a single copy of each chromosome. The probability of these plants to be generated in vivo without fusion of the gametes is very low, varying depending on the species from $2 \%$ in melon (Lotfi et al., 2003) to the $10 \%$ to $35 \%$ in some Brassica species (Foisset et al., 1997). Haploids can be obtained, depending on the species (Pauls, 1996), through in vitro culture of anthers or isolated microspores (androgenesis), ovules (gynogenesis), or in vitro rescue of parthenogenic embryos 
induced in situ through pollination with irradiated pollen (parthenogenesis).

In Cucurbitaceae species, haploid plants have been obtained by gynogenesis and parthenogenesis (Claveria et al., 2005; Gémesné-Juhász et al., 1997; Niemirowicz-Szczytt and Dumas de Vaulx, 1989; Przyborowski and Niemirowicz-Szczytt, 1994; Sari et al., 1994; Sauton, 1989; Yanmaz et al., 1999). In melon, the first haploids were obtained by intraspecific crosses (Dumas de Vaulx, 1979). Hereafter, gynogenesis and androgenesis were used without success (Dryanovska and Ilieva, 1983). Thus far, in situ-induced parthenogenesis through pollination with irradiated pollen is the method with best results to produce DHLs in melon (Sauton and Dumas de Vaulx, 1987). The pollination with irradiated pollen, at low irradiation levels, induces the growth of parthenocarpic fruit without zygotic embryos and the presence of some parthenogenic embryos of female gametophytic origin. Several factors can affect the haploid embryo generation rate, like the physiological stage of mother plants (Sauton, 1988a; Sestili and Ficcadenti, 1996), genotype (Cuny et al., 1992; Sauton, 1988b), pollen irradiation level (Cuny et al., 1992), or in vitro culture conditions (Sestili and Ficcadenti, 1996). Compared with other species of the Cucurbitaceae family, melon has a relatively better response than watermelon or zucchini to in situ-induced parthenogenesis (Przyborowski, 1996; Sauton and Dumas de Vaulx, 1987).

Marker-assisted selection using codominant molecular markers such as restriction fragment length polymorphism (RFLP) or microsatellites (SSR) allows for a rapid identification of actual DH from zygotic-originated plants based on their homozygosity. This strategy was successfully used in maize (Zea mays) and potato (Solanum chacoense) (Murigneux et al., 1993; Rivard et al., 1989). In addition, DHL populations can be indefinitely perpetuated by seed (Pauls, 1996) becoming very useful in genetic studies. Thus, DHLs are valuable in the development of genetic maps, particularly for long-term mapping projects, as a result of their unlimited plant material availability and because dominant and codominant markers can be mapped with the same precision because of their strict homozygosity (Burr and Burr, 1991; Gonzalo et al., 2005). DHL populations are also appropriate for the genetic dissection of quantitative traits. The fact that the same genotype can be studied in different locations and under different treatments makes DHL populations a suitable system to study in detail genotype $\times$ environment interaction (Pauls, 1996), allowing better estimates of major gene effects and quantitative trait loci (Monforte et al., 2004). In addition, the DHL populations have been used to generate advanced populations like near isogenic lines to augment the precision in genetic studies (Eduardo et al., 2005).

The importance of the melon crop and its high parthenogenic capacity justified the generation of a DHL population. For that reason, the main objectives of this work are, first, to study the response of different melon $(C$. melo) accessions to in situinduced parthenogenesis by pollination with $\gamma$-irradiated pollen followed by in vitro embryo rescue; second, to generate a DHL population from a selected hybrid; and third, to perform its molecular characterization.

\section{Materials and Methods}

Plant material and pollination with irRadiated pollen. To study the response of different cultivars to the in situinduced parthenogenesis by irradiated pollen, 17 genotypes were analyzed (Table 1). Eleven genotypes from $C$. melo ssp. melo belonging to the botanical variety inodorus $(\mathrm{PS}, \mathrm{T} \times \mathrm{L}, \mathrm{L} \times$ $\mathrm{Z}, 6 \times \mathrm{PS}, \mathrm{RQ} 200 \times \mathrm{PS}, \mathrm{M} 75 \mathrm{C} 164, \mathrm{M} 75 \mathrm{C} 167, \mathrm{M} 75 \mathrm{C} 257$, M81B520, 8, and M75CA155), three genotypes belonging to the botanical variety cantalupensis (M91, M92, and M93), one genotype from subspecies agrestis belonging to the botanical variety conomon (AG), one accession belonging to the botanical variety chinenis [the Korean accession PI 161375 ('Shongwan Charmi')], and one hybrid between the accession PI 161375 and PS were studied. Overall, two genotypes were inbred lines (PS and 8), two (AG and PI 161375) were originally open-pollinated landraces that were subjected to several generations of selfing until to obtain highly inbred genotypes, and the remaining 13 genotypes were $F_{1}$ hybrids. All the previous genotypes were used as female parents, from which parthenogenic embryos were rescued after pollination with the $\gamma$-irradiated pollen collected from the PS type (var. inodorus) inbred line M40. Female flowers from this line are monoecious, whereas flowers from the rest of the genotypes are andromonoecious. Melon flower sex expression is controlled by the gene $a$, being monoecious dominant over andromonoecious (Boualem et al., 2008), so sex expression in the hybrids between genotypes and the $\gamma$-irradiated M40 could be used as a morphological marker to discard hybrids produced by fertile M40 pollen. All the plant material, inbred lines, $F_{1}$ hybrids, and the monoecious pure line M40 were provided by Semillas Fitó (Barcelona, Spain), and because they are proprietary material, the pedigrees of these genotypes cannot be provided at this time.

A doubled haploid population was generated, during 4 years (consecutive), from the $\mathrm{F}_{1}$ hybrid derived from the PI 161375 , used as the maternal parent, and an inbred line of Spanish cultivar PS. Although the breeding line PS was chosen by its economic value in Spain, the female parent PI 161375 was selected for being a source of numerous disease resistance genes and because the genetic divergence between both genotypes is the maximum that has been described within melon germplasm (Dhillon et al., 2007; Garcia-Mas et al., 2000; Monforte et al., 2003; Oliver et al., 2001).

Daily collected male flowers, from M40, were irradiated with a $\mathrm{Co}^{60} \gamma$-ray source at a dose ranging between 250 and 500 Gy. Irradiated pollen was used the same morning after irradiation. Hermaphrodite flowers of the maternal lines or hybrids were emasculated and bagged $1 \mathrm{~d}$ before the corolla opened to avoid undesirable crosses. The next morning, while stigmas were receptive, pollination with irradiated M40 pollen was performed and flowers were bagged again.

IN VITRO EMBRYO RESCUE OF PUTATIVE PARTHENOGENIC EMBRYOS. Three to 5 weeks after pollination with $\gamma$-irradiated pollen, fruit were harvested, seeds extracted under sterile conditions, and in situ-induced putative parthenogenic embryos were rescued in vitro. Fruit were washed and disinfected by spraying their surface with $96 \%$ (v/v) ethanol. Parthenogenic embryos were identified by their morphology such as absence or asymmetric arrangement of cotyledons or other abnormalities (Fig. 1A-B). Twelve embryos with normal zygotic or doubtful parthenogenic morphology were cultured to test the selection process. Embryos were extracted from seeds and plated in petri dishes ( $6 \mathrm{~cm}$ diameter) with $10 \mathrm{~mL}$ of E20H8 medium (Claveria et al., 2005). Cultures were incubated at $28{ }^{\circ} \mathrm{C}$ with a 16 -h photoperiod $\left(50 \mu \mathrm{mol} \cdot \mathrm{m}^{-2} \cdot \mathrm{s}^{-1}\right)$. Up to four subcultures to fresh medium were done every 2 weeks until all viable embryos developed (Fig. 1C). Plantlets were transferred 
Table 1. Response of different melon genotypes to in situ-induced parthenogenesis after pollination with $\gamma$-irradiated pollen and in vitro embryo rescue.

\begin{tabular}{|c|c|c|c|c|c|c|c|c|c|c|}
\hline \multirow[b]{2}{*}{ Cucumis melo type ${ }^{\mathrm{z}}$} & \multirow[b]{2}{*}{$\begin{array}{c}\text { Genotype } \\
\text { code }^{\mathrm{y}}\end{array}$} & \multirow[b]{2}{*}{$\begin{array}{l}\text { Fruit } \\
(\text { no. })^{\mathrm{x}}\end{array}$} & \multirow[b]{2}{*}{$\mathrm{S}(\text { no. })^{\mathrm{x}}$} & \multicolumn{4}{|c|}{ Putative parthenogenic embryos ${ }^{\mathrm{x}}$} & \multicolumn{3}{|c|}{$\mathrm{DHLs}^{\mathrm{x}}$} \\
\hline & & & & $\begin{array}{l}\mathrm{CE} \\
\text { (no.) }\end{array}$ & $\mathrm{CE} / 500 \mathrm{~S}$ & $\begin{array}{l}\mathrm{RE} \\
\text { (no.) }\end{array}$ & $\mathrm{RE} / \mathrm{CE}$ & $\begin{array}{l}\text { Fertile } \\
\text { (no.) }\end{array}$ & $\mathrm{DHL} / \mathrm{RE}$ & DHLs/500S \\
\hline \multicolumn{11}{|l|}{ ssp. melo var. inodorus } \\
\hline Piel de sapo & PS & 6 & 3480 & 11 & 1.58 & 7 & 0.64 & 3 & 0.43 & 0.43 \\
\hline Piel de sapo & $\mathrm{T} \times \mathrm{L}$ & 48 & 10999 & 12 & 0.55 & 5 & 0.42 & 2 & 0.40 & 0.09 \\
\hline Piel de sapo & $\mathrm{L} \times \mathrm{Z}$ & 33 & 18049 & 49 & 1.36 & 44 & 0.90 & 23 & 0.52 & 0.64 \\
\hline Piel de sapo & $6 \times$ PS & 66 & 30756 & 167 & 2.71 & 138 & 0.83 & 45 & 0.33 & 0.73 \\
\hline Piel de sapo & RQ200 × PS & 99 & 47136 & 219 & 2.32 & 172 & 0.79 & 64 & 0.37 & 0.68 \\
\hline Piel de sapo & M75C164 & 3 & 1365 & 1 & 0.37 & 0 & 0.00 & - & - & - \\
\hline Piel de sapo & M75C167 & 3 & 2256 & 9 & 1.99 & 2 & 0.22 & 2 & 1.00 & 0.44 \\
\hline Piel de sapo & M75C257 & 3 & 1354 & 8 & 2.95 & 3 & 0.38 & 3 & 1.00 & 1.11 \\
\hline Piel de sapo & M81B520 & 5 & 4125 & 13 & 1.58 & 5 & 0.38 & 5 & 1.00 & 0.61 \\
\hline Yellow & 8 & 3 & 1551 & 2 & 0.64 & 2 & 1.00 & 0 & 0.00 & 0.00 \\
\hline Yellow & M75CA155 & 2 & 1057 & 0 & 0.00 & - & - & - & - & - \\
\hline \multicolumn{11}{|c|}{ ssp. melo var. cantalupensis } \\
\hline Cantalupe smoth & M91 & 8 & 6133 & 26 & 2.12 & 11 & 0.42 & 10 & 0.91 & 0.82 \\
\hline Cantalupe ribbed & M92 & 6 & 3242 & 18 & 2.78 & 4 & 0.22 & 4 & 1.00 & 0.62 \\
\hline Galia & M93 & 6 & 3345 & 1 & 0.15 & 0 & 0.00 & - & - & - \\
\hline \multicolumn{11}{|c|}{ ssp. agrestis var. conomon ${ }^{\mathrm{w}}$} \\
\hline Agrestis & $\mathrm{AG}$ & 3 & 1446 & 6 & 2.07 & 3 & 0.50 & 1 & 0.33 & 0.35 \\
\hline \multicolumn{11}{|c|}{ ssp. agrestis var. chinensis } \\
\hline Songwham Charmi & PI 161375 & 8 & 5279 & 21 & 1.99 & 5 & 0.24 & 3 & 0.60 & 0.28 \\
\hline \multicolumn{11}{|c|}{$\begin{array}{l}\text { ssp. agrestis var. chinensis } \times \\
\text { ssp. melo var. inodorus }\end{array}$} \\
\hline & PI $161375 \times$ PS & 250 & 201450 & 527 & 1.31 & 316 & 0.60 & 109 & 0.34 & 0.27 \\
\hline $\begin{array}{l}{ }^{\mathrm{z}} \text { Based on the Pitrat et } \\
{ }^{\mathrm{y}} \text { Inbred lines (PS and } \\
161375 \text { ), and F1 hybri } \\
161375 \times \text { PS). } \\
{ }^{\mathrm{x}} \text { Fruit }=\text { fruit after polli } \\
\mathrm{CE} / 500 \mathrm{~S}=\text { in vitro-cul } \\
\text { doubled haploid lines } \\
\text { rescued embryos; DHL } \\
{ }^{\mathrm{w}} \text { Origin in East Asia; }\end{array}$ & $\begin{array}{l}\text { l. }(2000) \text { classific } \\
) \text { open-pollinated } \\
(\mathrm{T} \times \mathrm{L}, \mathrm{L} \times \mathrm{Z}, 6 \\
\text { ation with } \gamma \text {-irradi } \\
\text { ured embryos ove } \\
\text { ith seed; Fertile }= \\
/ 500 \mathrm{~S}=\text { doubled } \mathrm{h} \\
\text { ame proposed var. }\end{array}$ & $\begin{array}{l}\text { tion. } \\
\text { andrace } \\
\text { PS RQ2 } \\
\text { ted polle } \\
500 \text { seec } \\
\text { loubled } \\
\text { ploid lin } \\
\text { conomor }\end{array}$ & $\begin{array}{l}\text { subjected } \\
00 \times \mathrm{PS}, \mathrm{N} \\
\mathrm{n} ; \mathrm{S}=\text { seed } \\
; \mathrm{RE}=\text { in } \\
\text { laploid pla } \\
\text { s with see }\end{array}$ & $\begin{array}{l}\text { to sever } \\
75 \mathrm{C} 164 \\
\text { rom fru } \\
\text { tro resc }\end{array}$ & $\begin{array}{l}\text { generations } \\
\text { 175C } 167, \mathrm{~N} \\
\text { after pollina } \\
\text { d embryos; } \\
\text { ated by see } \\
\text { eed. Value }\end{array}$ & $\begin{array}{l}\text { f selfin } \\
\text { C257, } \\
\text { n with } \\
\text { E/CE = } \\
\text { DHL/R }\end{array}$ & $\begin{array}{l}\text { obtain } \\
\text { dib520, } \\
\text { vitiated po resc } \\
=\text { doubled } \\
\text { ums or ra }\end{array}$ & $\begin{array}{l}\text { Shly inb } \\
\text { 75CA15 } \\
\text { en; CE }= \\
\text { ed over } \\
\text { aploid li } \\
\text { os group }\end{array}$ & $\begin{array}{l}\text { d genotype } \\
\text { M91, M92 } \\
\text { n vitro cult } \\
\text { litured emb }\end{array}$ & $\begin{array}{l}\text { (AG and PI } \\
\text { M93, and PI } \\
\text { red embryos; } \\
\text { yos; DHLs = } \\
\text { over in vitro } \\
\text { ch genotype. }\end{array}$ \\
\hline
\end{tabular}

to tubes, and later on to flasks, with E20H8 medium after micropropagation by axillary branching. During micropropagation, cultures were incubated at a higher light intensity $\left(70 \mu \mathrm{mol} \cdot \mathrm{m}^{-2} \cdot \mathrm{s}^{-1}\right)$. At this stage, haploid plants were treated with colchicine to double their chromosome number (Fig. 1D). Plantlets with a good root system and four to six normal leaves were acclimated in peat plugs (Jiffy-7; Jiffy Products España, Puerto Lumbreras, Murcia, Spain) and brought to the greenhouse for selfing (Fig. 1E).

Gametophytic ORIGin and Ploidy Determination. The origin of lines recovered by in vitro embryo rescue was determined by the codominant molecular markers patterns [SSRs or RFLPs (see subsequently)] complemented with the ploidy level, which was determined by flow cytometry. Lines homozygous for the molecular markers might be spontaneous diploids, but haploids must be identified before chromosome doubling. Lines heterozygous for any of the markers used, therefore originated from zygotic embryos, were eliminated. Zygotes could originate from viable pollen of M40 unaffected by $\gamma$-ray irradiation or from uncontrolled pollinations. Lines homozygous for all SSRs and RFLPs, presumably originated from parthenogenic embryos, were maintained in vitro until their ploidy level was determined. Flow cytometry was used to determine the DNA content of each line during in vitro micropropagation and after in vitro colchicine treatment. Young leaves from actively growing plants were finely chopped and macerated for $5 \mathrm{~min}$ into $2 \mathrm{~mL}$ LB01 lysis buffer (DolcetSanjuan et al., 1997) with 2\% (v/v) Triton X-100 (SigmaAldrich, Madrid, Spain) to release intact nuclei. The supernatant was filtered through a 56- $\mu \mathrm{m}$ nylon mesh. The nuclei were labeled with propidium iodide, and red fluorescence was analyzed using a 675-nm band-pass filter. Results were presented in a histogram (Fig. 1D) expressing the distribution of nuclei according to the red fluorescence intensity, which is proportional to the DNA content. Leaves from in vitro-maintained diploid and haploid melon plants were used as controls.

Chromosome doubling OF HAPLOID Plants. Most of the in vitro rescued lines were haploid, and therefore chromosome doubling was necessary to recover fertile plants. Micropropagation of haploid lines was required before their chromosome number was doubled in vitro with a colchicine (Sigma-Aldrich) treatment similar to the one described in Claveria et al. (2005). 

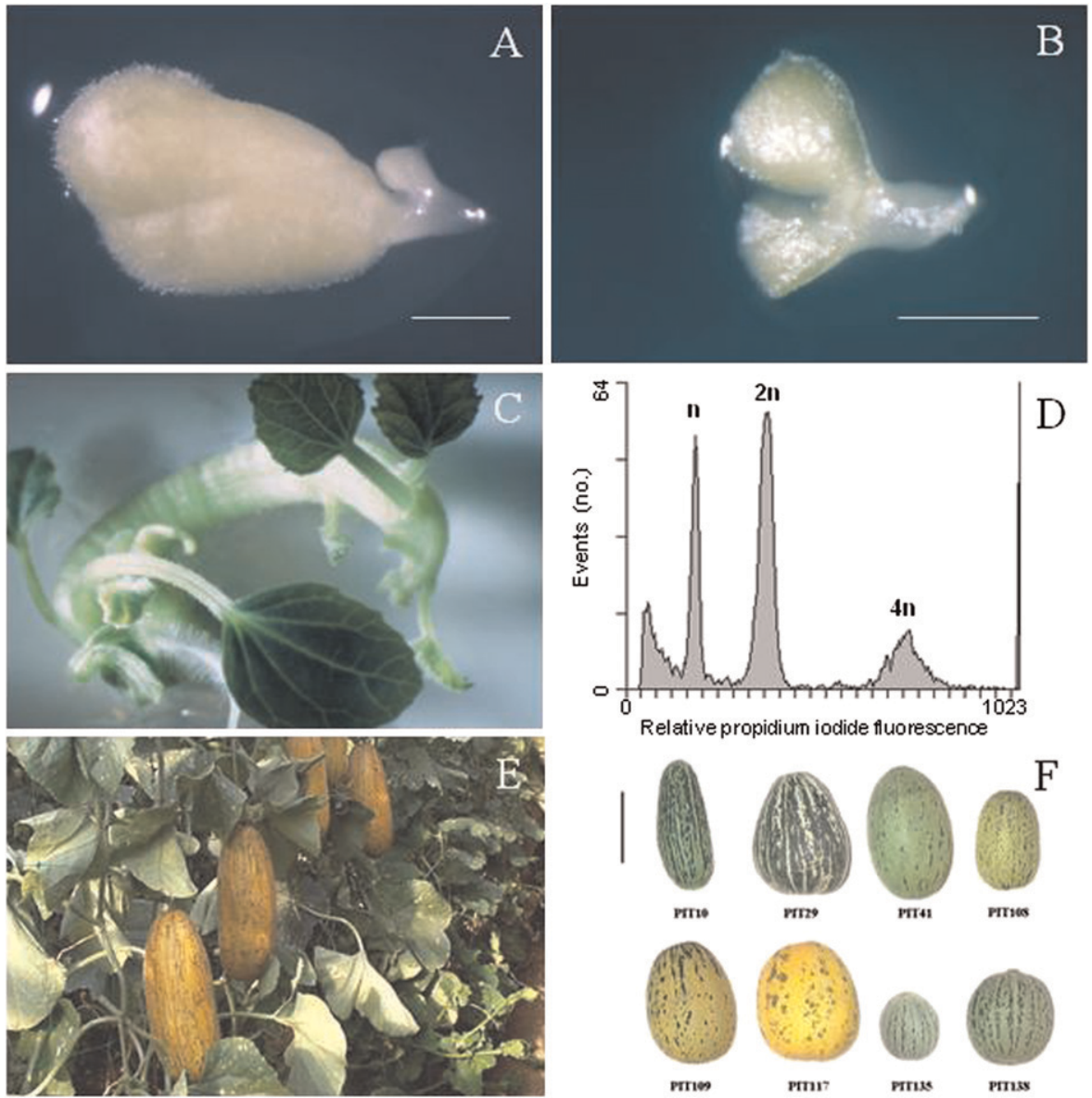

2n

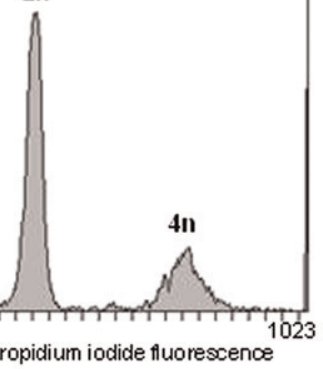

Fig. 1. Melon doubled haploid lines produced through in situ-induced parthenogenesis. Parthenogenic embryos, 3 weeks after pollination with $\gamma$-irradiated pollen, with abnormal and asymmetric cotyledons $[\mathbf{A}-\mathbf{B}(\mathrm{bar}=1 \mathrm{~mm})]$. Developed plantlet 3 weeks after in vitro culture $(\mathbf{C})$. Histogram of flow cytometric analysis of DNA content of nuclei released from leaves of a haploid line treated with colchicine (D). Perpetuation of doubled haploid plants by self-pollination (E). Fruit variability from several doubled haploid lines derived from the PI $1613175 \times$ 'Piel de Sapo’ hybrid $[\mathrm{F}($ bar $=10 \mathrm{~cm})]$.

Two hundred shoot explants of each line, with one or two axillary buds each, were cultured in E20H8 solid medium supplemented with $500 \mu \mathrm{M}$ colchicine dissolved in dimethyl sulfoxide (Sigma-Aldrich). Explants were cultured in petri dishes (10 cm diameter) or polystyrene microboxes (RA40; Combiness, Gent, Belgium), 20 to 40 explants each, respectively. This treatment with colchicine was chosen as the most effective in doubling the chromosome number in melon after comparing it with trifluralin and oryzalin, all at five concentrations ranging from 100 and $1000 \mu \mathrm{M}$ (data not shown). After $48 \mathrm{~h}$, explants were transferred to solid colchicine-free E20H8 medium. Flow cytometry confirmed chromosome doubling of haploid plants, which in most cases were chimerical plants with haploid and diploid sectors (Fig. 1D). Twenty doubled haploid rescued plants per line were transferred to the greenhouse and selfed in 2 consecutive years to perpetuate them by seed and therefore become DHLs.

GENOTYPE EFFECT ON DOUBLED HAPLOID LINE PRODUCTION. The response of the melon genotypes to the DHL generation process was divided into three consecutive steps; first, the capacity to produce parthenogenic embryos, expressed by the number of in vitro-cultured parthenogenic embryos over 500 seed $(\mathrm{CE} / 500 \mathrm{~S})$; second, the in vitro success in rescuing such embryos into plants, expressed by the number of rescued over the in vitro cultured parthenogenic embryos (RE/ $\mathrm{CE}$ ); and third, the aptitude of the micropropagated doubled haploid plants to be perpetuated by seed, which was expressed by the number of DHLs over rescued embryos (DHL/ RE). Pearson correlation coefficients among the three different steps, defined for DHL development, were calculated using JMP (Version 5.1.2 for Windows; SAS Institute, Cary, NC).

DOUBLED HAPLOID LINE HOMOZYGOSITY DETERMINATION. To confirm DHLs' homozygosity, RFLP and SSR molecular markers were used as described by Gonzalo et al. (2005). Briefly, genomic DNA was extracted from young leaf tissue according to Doyle and Doyle (1990). In addition, purification by Cesium chloride gradient was performed to obtain a high-quality DNA. The DHLs were genotyped with 78 RFLP markers (Baudracco-Arnas and Pitrat, 1996; Oliver et al., 2001) and 86 SSR markers (Danin-Poleg et al., 2001; Fazio et al., 2002; Gonzalo et al., 2005; Katzir et al., 1996) that were evenly distributed along the genome (Gonzalo et al., 2005).

AlleliC FREQUENCY SEGREGATION. The percentage of PS and PI 161375 genome in each DHL was obtained using the software Graphical GenoTypes (Van Berloo, 2008). Segregation distortion at each marker locus was tested against the expected ratios (1:1 for DHL) using a chi-square test with Joinmap 3.0 (Van Ooijen and Voorrips, 2001). Distortion was declared significant at $P<0.005$.

\section{Results and Discussion}

RESPONSE OF DIFFERENT MELON TYPES TO IN SITU-INDUCED PARTHENOGENESIS. The results of the 17 analyzed genotypes, considering the three stages of the DHL generation process, are summarized in Table 1. Like in most of the in vitro culture processes, the genotype was a determinant factor in the efficiency of DHL production. The response of the melon genotypes to in situ parthenogenesis induced by $\gamma$-irradiated pollen was different between and within subspecies. Embryos of all the genotypes analyzed were obtained in the first step of the DHL generation process $(\mathrm{CE} / 500 \mathrm{~S})$, although differences in the number of embryos among genotypes were observed. In this step, the mean values were not notably different among the botanical varieties. The capacity to produce parthenogenic embryos ranged from 0.37 to $2.95 \mathrm{CE} / 500 \mathrm{~S}$ in the genotypes of the var. inodorus and from 0.15 to $2.78 \mathrm{CE} / 500 \mathrm{~S}$ for the var. cantalupensis. The two genotypes from ssp. agrestis, var. conomon and var. chinensis, showed 2.07 and $1.99 \mathrm{CE} / 500 \mathrm{~S}$, 
respectively, and 1.31 CE/500S were obtained from the hybrid PI $161375 \times$ PS.

The embryo survival rate (RE/CE) was variable within and between subspecies and independent of the embryos obtained from parthenocarpic fruit (CE/500S; Table 2). This was the limiting step for some cultivars with the loss of all embryos, as in the case of M75C164 and M93 (Table 1). For other genotypes, the number of rescued embryos was reduced to half, whereas in the case of $\mathrm{L} \times \mathrm{Z}$ and line 8 , almost all embryos survived. The rescue of embryos in vitro was also the limiting step for var. chinensis PI 161375, the maternal parent of the hybrid later used to generate the DHL population, whereas for PS, this rate was three times higher.

Finally, in the last stage, not all the acclimated DH plants were perpetuated by seed and were therefore counted as DHL. The number of fertile lines (DHL/RE) varied considerably with the genotype (Table 1). This was the limiting step for two of the genotypes with a higher number of parthenogenic embryos $(6 \times$ PS and RQ200 $\times$ PS $)$. The production of fertile DHL was relatively high for the two cantaloupe hybrids (C. melo ssp. melo var. cantalupensis), whereas it was the limiting step for the accessions belonging to ssp. agrestis. In previous works (Pauls, 1996), the number of DHLs perpetuated by seed, after colchicine treatment, decreased to half in some genotypes as a result of low fertility after selfing in the greenhouse or poor seed germination caused by lethal or sublethal effects of recessive alleles.

These results showed the heterogeneous response of the melon cultivars in the different steps of the DHL generation process. In general, the limiting step was different for each genotype. Because the experimental conditions were similar for all the assayed genotypes, the differences in the response should be the result of the strong influence of the genotype on haploid production in melon as it had been reported previously by different authors (Ficadenti et al., 1995; Sauton, 1988b; Sestili and Ficcadenti, 1996). The number of parthenogenic embryos obtained was slightly inferior to the results from other works, in which the embryo percentage by open seed fluctuated between 3.4\% (Cuny et al., 1992, 1993) and 2.5\% (Sauton and Dumas de Vaulx, 1987). However, the number of surviving embryos during the in vitro culture phase was higher than the results obtained in others works, in which the percentage of rescue embryos was near 29\% (Cuny et al., 1992). The decrease of viable embryos along the in vitro rescue (RE/CE) could be the result of the process itself, as described by Pauls (1996), including the colchicine treatment. However, a more efficient protocol was followed in the present work when compared with the results

Table 2. Correlations between the efficiencies found in four consecutive steps of the in situ-induced parthenogenesis protocol used to generate doubled haploid lines from different melon genotypes.

\begin{tabular}{lcccc}
\hline & $\mathrm{CE} / 500 \mathrm{~S}^{\mathrm{z}}$ & $\mathrm{RE} / \mathrm{CE}^{\mathrm{z}}$ & $\mathrm{DHL} / \mathrm{RE}^{\mathrm{z}}$ & $\mathrm{DHL} / 500 \mathrm{~S}^{\mathrm{z}}$ \\
\hline $\mathrm{CE} / 500 \mathrm{~S}$ & 1 & -0.12 & $0.38^{*}$ & $0.73^{* *}$ \\
$\mathrm{RE} / \mathrm{CE}$ & - & 1 & $-0.68^{* *}$ & 0.14 \\
$\mathrm{DHL} / \mathrm{RE}$ & - & - & 1 & $0.50^{* *}$ \\
$\mathrm{DHL} / 500 \mathrm{~S}$ & - & - & - & 1 \\
\hline
\end{tabular}

${ }^{\bar{z}} \mathrm{CE} / 500 \mathrm{~S}=$ in vitro-cultured embryos over 500 seed; $\mathrm{RE} / \mathrm{CE}=$ in vitro rescued over cultured embryos; DHL/RE = doubled haploid lines over in vitro rescued embryos; DHL/500S = doubled haploid lines over 500 seed. Pearson correlation coefficients were calculated using JMP (Version 5.1.2 for Windows; SAS Institute, Cary, NC).

$* P<0.05 ; * * P<0.01$. reported by other authors (Lim and Earle, 2008, 2009). In most of the previous reported works (Cuny et al., 1992, 1993; Sauton and Dumas de Vaulx, 1987) oriented toward melon DHL generation, the total number of plants obtained was not mentioned. Lotfi et al. (2003) reported their efficiency in the production of haploid lines with rates between $61 \%$ and $75 \%$, which are close to the results obtained in the present work (Table 1; RE/CE). However, in the selfing process, they observed that the percentage decreased, signaling that only some of the plants produced viable seeds, although the final number of DHLs obtained from rescued embryos was not reported. In the present work, the number of DHLs perpetuated by seed varies from 0.1 to $1.1 / 500$ seeds (Table 1; DHL/500S). In conclusion, the differences reported in the DHL efficiency production could be the result of the culture conditions, but most probably the distinct genotypes used in the different works.

The correlations between the values obtained in the different steps of the DHL generation were calculated (Table 2). A positive significant correlation (0.38) between the cultured embryos (CE/500S) and the DHL obtained (DHL/RE) was observed. However, the correlation between the proportion of rescued embryos relative to cultured embryos (RE/CE) and the DHL obtained (DHL/RE) was significant and negative. This suggests that during the in vitro culture process, there is a high selection pressure, which allows only for the survival of the viable embryos without developmental abnormalities induced by deleterious recessive alleles in homozygosity in haploid plants (Cuny et al., 1992). Despite that, the number of surviving embryos for some genotypes was higher in the present work (Table 1; RE/CE) than in other works (Cuny et al., 1992), in which the percentage of rescued embryos that became double haploid plants was near the $29 \%$.

The response of the PI $161375 \times$ PS hybrid to the in situinduced parthenogenesis was compared with the parental lines PI 161375 and PS (Table 1). The values obtained in the three defined stages (CE/500S, RE/CE, and DHL/RE) were closer to PS than PI 161375. Only the RE/CE value for the hybrid is within the range limited by the response of both parents. For the other two ratios (CE/500S and DHL/RE), the response of the hybrid was lower than PS. On the contrary, the final number of DHL in the hybrid $(0.24 \mathrm{DHL} / 500 \mathrm{~S})$ was closer to the PI 161375 (0.28 DHL/500S) than PS (0.43 DHL/500S). Thus, the last stage (DHL/RE) could be considered the limiting one for the generation of DHL in the hybrid. In previous works with melon (Cuny et al., 1993), the parthenogenic response of $F_{1}$ hybrids was reported to be closer to the female parental. In the case of the PI $161375 \times$ PS hybrid, the global response (DHL/ 500S) was also closer to that of the female parent PI 161375. However, the ratios expressing the three consecutive phases of the process $(\mathrm{CE} / 500 \mathrm{~S}, \mathrm{RE} / \mathrm{CE}$, and DHL/RE) indicated a closer response of the hybrid to the male than female parent. This may suggest a role of PS and the participation of alleles from both parents in the different steps of the DHL generation process. This confirms also the strong influence of the genotype in the DHL generation and the importance of determining the limiting steps for each genotype. Furthermore, the results suggest the need for preliminary trials to determine the steps that could limit the massive generation of DHLs by in situ-induced parthenogenesis.

GENERATION AND MOLECULAR EVALUATION OF DOUBLED HAPLOID LINES DERIVED FROM THE $\mathbf{F}_{\mathbf{1}}$ HYBRID PI $161375 \times$ 'PIEL DE SAPO'. In the DHL generation process, one of the most important steps is the selection method of the lines, emphasizing the fact 


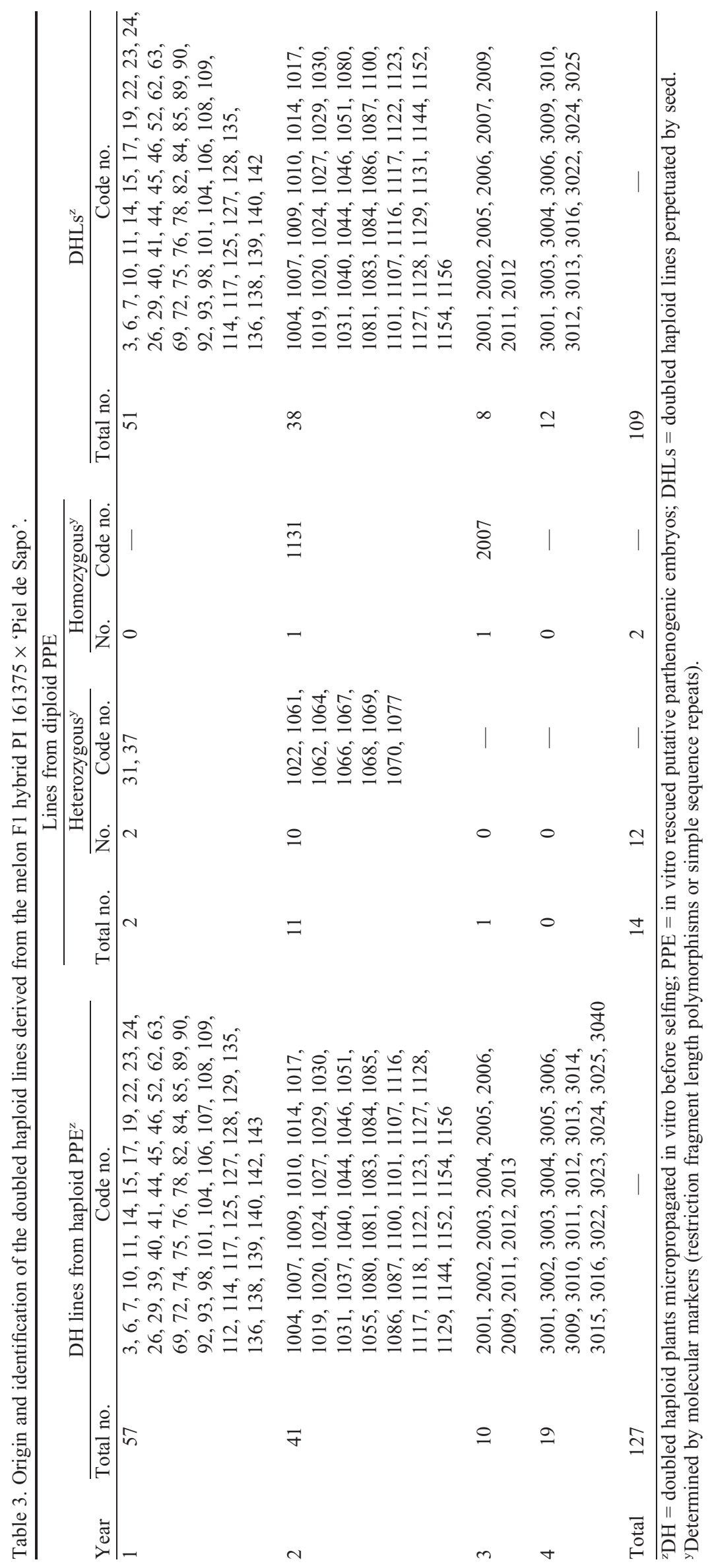


that all the selected lines should be doubled haploid and fertile. To accomplish it, morphological and molecular selection tools, in the different stages of the process, were used. The first selection was based on the morphology of the embryos, because putative parthenogenic embryos (PPE) are smaller than zygotic and present asymmetric, abnormal, or absence of cotyledons (Fig. $1 \mathrm{~A}-\mathrm{B})$. As a result of the morphological selection, a total of 141 plants, 127 haploid and 14 diploid, were obtained (Table 3), 12 of which were from embryos with normal zygotic or doubtful parthenogenic morphology. The second screening of plants was performed by flow cytometry to determine the ploidy level. Of the 141 plants, 127 lines were haploid, whereas the remaining 14 were diploid without a visible haploid phase. The origin of all the lines was confirmed by a third selection test using RFLP and SSR molecular markers (Fig. 2). The use of codominant markers was previously reported as a useful method to identify DH plants produced by anther culture (Rivard et al., 1989). In the present work, codominant markers were not only useful to determine the gametophytic origin, but also to discriminate those derived from crosses with the irradiated pollen. In our population, the analysis with molecular markers detected 12 heterozygous lines, which corresponded to the lines with normal zygotic or doubtful parthenogenic morphology. After the confirmation with the molecular markers, these lines were eliminated. Two lines derived from PPE were diploid and homozygous for all the molecular markers analyzed and consequently they were considered DHLs. The occurrence of these two lines could be the result of spontaneous duplication in the chromosome number and resulted in a total of 129 DHLs, 127 from haploid plants and two from diploid plants. In agreement with it, this phenomenon has been described previously in melon with a rate of one plant by 44 rescued embryos (Sauton, 1988a) and in cucumber with two plants by 23 embryos (Niemirowicz-Szczytt and Dumas de

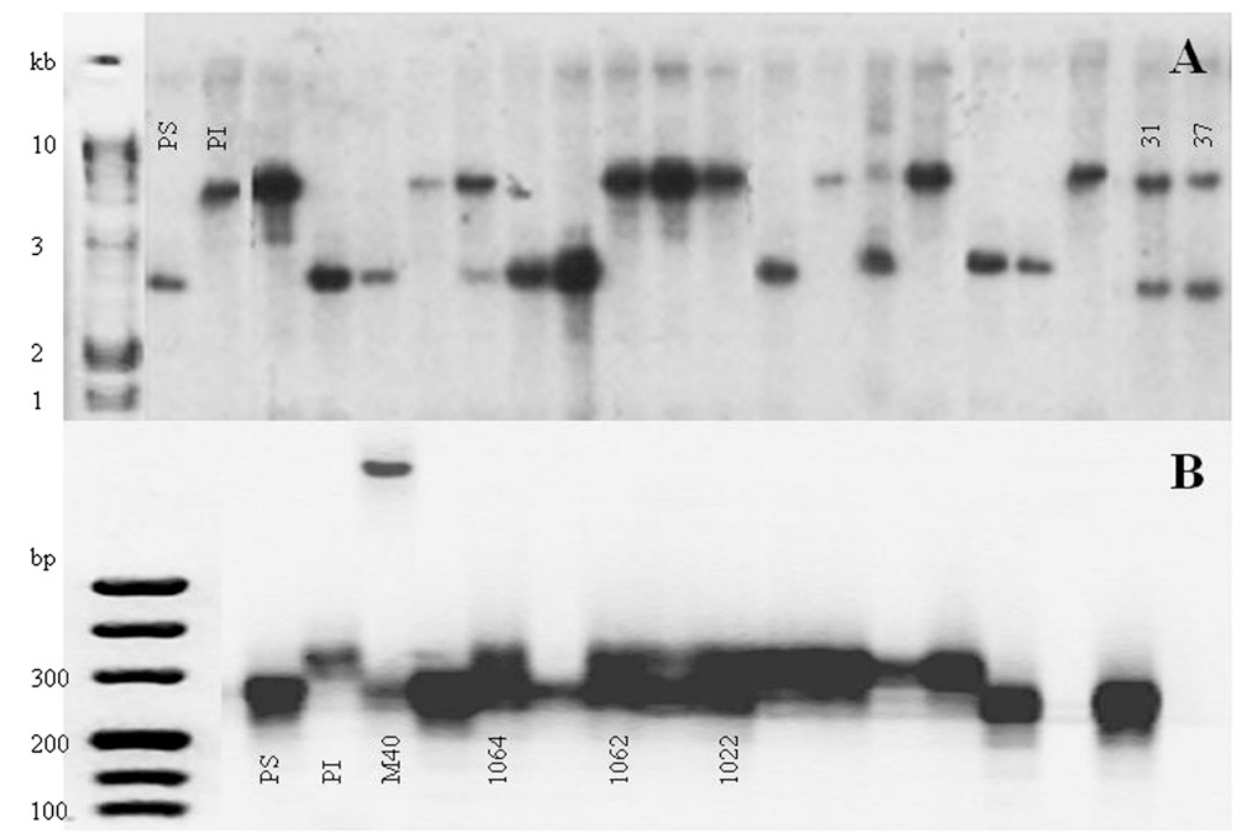

Fig. 2. Band pattern of two molecular markers for both melon parents, PI 161375 (PI) and 'Piel de Sapo' (PS) and several lines. The analysis with the restriction fragment length polymorphism marker MC127 (A) detected two heterozygous lines, 31 and 37. The analysis with the CMCTN5 simple sequence repeat marker (B) discerned among the two parents and the pollen donor (M40). Lines 1022, 1062, and 1064 showed the band of both parents confirming their heterozygosity and the absence of pollen donor (M40) contamination.
Vaulx, 1989). Furthermore, the use of molecular markers that can discern among the two parents and the pollen donor, M40, allowed confirming the zygotic origin of the lines, by selfpollination, because contamination with M40 pollen was not detected (Fig. 2B). Thus, the 12 heterozygous plants, which appeared during the in vitro process, were produced after accidental self-pollination of the hybrid, as previously reported by Murigneux et al. (1993), who stated that such plants are most likely to occur as a result of selfing and sampling errors.

At the end of the 4-year-long process, a total of 129 DHLs were obtained, and 109 of them were perpetuated by seed, resulting in a fertility percentage of $84.5 \%$. These results confirm the efficiency of the selection based on the morphology because all the embryos with normal zygotic or doubtful parthenogenic morphology were heterozygous. The efficiency of this type of selection was previously reported by Sauton and Dumas de Vaulx (1987). It is also remarkable the high fertility observed after colchicine treatment of the haploid lines derived from the PI $161375 \times$ PS hybrid, because viable seed were obtained from $84.3 \%$ of the haploid lines (107 fertile over 127 total haploid lines) and $100 \%$ of the diploid lines (two fertile over two diploid homozygous lines). This could be the consequence of the interaction between the genome of both parents with a large genetic distance (Garcia-Mas et al., 2000). Compared with other genotypes (Table 1), the level of fertility of the lines derived for this hybrid was not superior, although they were produced following the same protocol.

Allelic Composition of doubled haploid lines. Ninetyfive of the generated DHLs were analyzed with 169 codominant molecular markers previously reported (Gonzalo et al., 2005). The expected percentage of genome from each parental was $50 \%$, assuming non-directional selection during the DHL production. The average percentage of PI 161375 genome among the lines was $48.8 \%$ (Fig. 3), as it was reported by Eduardo et al. (2005), ranging from $20 \%$ and $70 \%$ of PI 161375 genome. However, in the analysis of the allelic segregation at a single marker level, $17.75 \%$ of the 169 markers presented a significant deviation from the expected 1:1 segregation ratio (Gonzalo et al., 2005). Markers with distortion in their allelic frequencies mapped at six different genomic regions (Fig. 4). In the linkage groups VII and VIII, the distortion was favorable to the PI 161375 allele, whereas in linkage groups I, II, VI, and XI, the distortion was favorable to the PS allele. Distortion from expected allele frequencies of genetic loci in DHL populations has been reported by several authors (Chani et al., 2002; Guiderdoni, 1991; Manninen, 2000; Thompson et al., 1991; Zivy et al., 1992). These segregations are more frequent in DHL populations than in sexually based populations, as single seed descents or $\mathrm{F}_{2}$ (Foisset and Delourme, 1996), probably as a result of the 


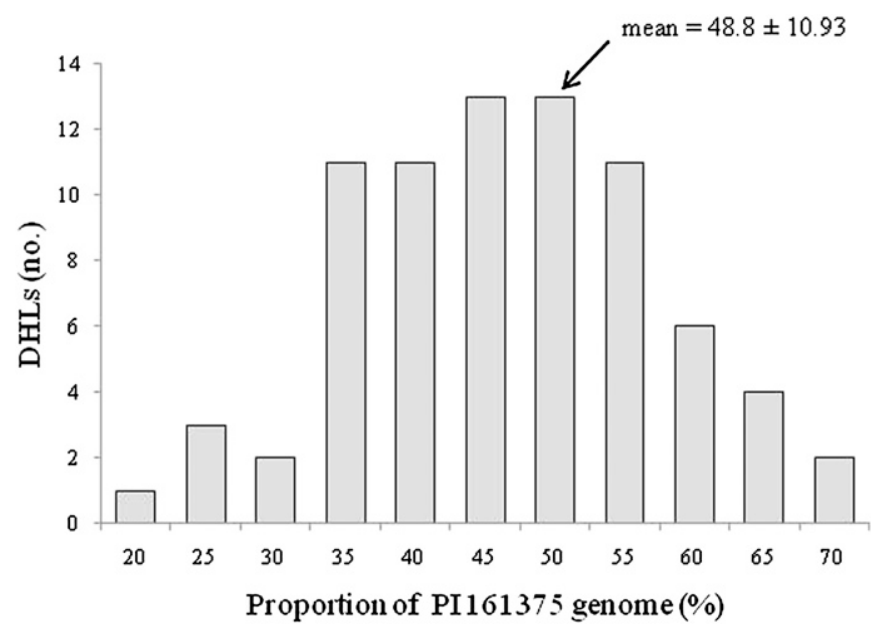

Fig. 3. Distribution of the PI 161375 genome percentage among the doubled haploid line population, derived from the melon PI $161375 \times$ 'Piel de Sapo' hybrid. Mean and SD of this percentage for the whole doubled haploid line population are indicated above the histogram.
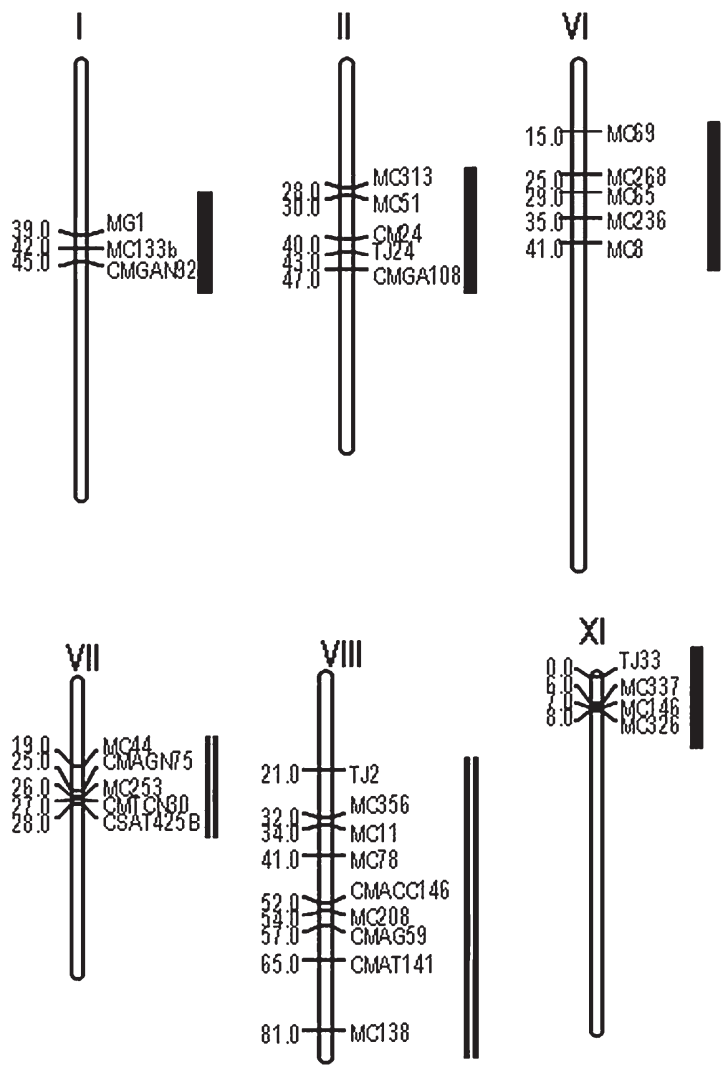

Fig. 4. Genomic regions showing significant $(P<0.005)$ segregation distortion toward the PI $161375(=)$ or the 'Piel de Sapo' ( $(-)$ melon parents modified from Gonzalo et al. (2005). Linkage group nomenclature is according to Perin et al. (2002).

selection pressure exerted during the in vitro culture process with favorable selection of alleles that beneficed the regeneration or the negative selection against lethal or semilethal alleles (Murigneux et al., 1993; Pauls, 1996; Rivard et al., 1989) and also by drift during the process. Thus, genomic regions showing segregation distortion are candidates to contain genes involved in the adaptation and response of the plants to the in vitro processes (Foisset and Delourme, 1996; Manninen, 2000; Rivard et al., 1989). In accordance to what is shown in Table 1, alleles from both parental lines might contribute to the final response of the hybrid to the generation of DHLs.

In melon, distortion in the allelic segregation has been reported in $\mathrm{F}_{2}$ (Baudracco-Arnas and Pitrat, 1996; Oliver et al., 2001), backcross (Wang et al., 1997), and recombinant inbred (Perin et al., 2002) populations. The proportion of markers showing distortion in this work (17.75\%) was in general higher than that observed in the previous studies with $12 \%$ in Baudracco-Arnas and Pitrat (1996), 14\% in Wang et al. (1997), 5.8\% in Oliver et al. (2001), and 19.8\% in Perin et al. (2002), although the comparison cannot be direct because most of the previous works used a lower statistical threshold to declare significant distortion (usually $P<0.05$, although we used $P<0.005)$ and also a high proportion of the markers used in previous works were anonymous and dominant, which may display distortion as a result of other causes than actual segregation distortion at a single genetic locus. Comparing segregation distortion with the Oliver et al. (2001) $\mathrm{F}_{2}$ population derived from the same cross, five of the distorted regions were exclusive of the current DHL population. Eduardo et al. (2005) did not observe segregation distortion during the several backcrosses performed to develop introgression lines from the same cross. These two evidences from sexually originated populations from the same cross support that the higher number of distorted genome regions found in the DHL population is caused by selective processes during the in vitro generation of parthenogenic DHL as was previously described for the generation of androgenic DHLs in other crops (Chani et al., 2002). Four of these distorted regions showed a higher frequency of PS alleles and only one was favorable to PI 161375. In different crops like barley (Hordeum vulgare) (Graner et al., 1991; Manninen, 2000; Zivy et al., 1992) or maize (Bentolila et al., 1992; Murigneux et al., 1993), the distortion of the allelic frequencies reported in $\mathrm{DH}$ populations were in all the cases favorable to the parent with a better response in the DHL generation. In the current report, PS showed a better response in one $(\mathrm{RE} / \mathrm{CE})$ of the three steps defined for the DHL generation process (Table 1) and the hybrid had a response closer to PS in this ratio. In the other two steps (CE/500S and DHL/RE), PI 161375 was superior to PS; however, the hybrid has a response closer to PS in both ratios. That could explain the major number of regions with segregation favorable to the PS genotype and the appearance of fewer regions distorted for PI 161375. The presence of regions with distortion favorable for both lines would explain their differential role in the generation of DHL.

In conclusion, the important effect of the genotype in the DHL generation process in melon recommends a preliminary analysis of the genotype's performance following the protocol described here to increase the process efficiency and to get better knowledge of the limiting steps affecting each melon cultivar. Furthermore, the use of molecular markers to analyze the DHL homozygosity provides an excellent tool to discard the zygotic lines or to detect contamination resulting from the pollen donor or other cultivars. This technique accelerates the selection of lines, one of the critical stages in the DHL generation process. As well, the information of the allelic frequencies provided by the molecular marker analysis indicates the contribution of each parent in the generation of DHL populations. 


\section{Literature Cited}

Baudracco-Arnas, S. and M. Pitrat. 1996. A genetic map of melon (Cucumis melo L.) with RFLP, RAPD, isozyme, disease resistance and morphological markers. Theor. Appl. Genet. 93:57-64.

Bentolila, S., C. Hardy, C. Guitton, and G. Freyssinet. 1992. Comparative genetic analyses of $\mathrm{F}_{2}$ plants and anther culture derived plants of maize. Genome 35:575-582.

Boualem, A., M. Fergany, R. Fernandez, C. Troadec, A. Martin, H. Morin, M.A. Sari, F. Collin, J.M. Flowers, M. Pitrat, M.D. Purugganan, C. Dogimont, and A. Bendahmane. 2008. A conserved mutation in an ethylene biosynthesis enzyme leads to andromonoecy in melons. Science 321:836-838.

Burr, B. and A.F. Burr. 1991. Recombinant inbreds for molecular mapping in maize: Theoretical and practical considerations. Trends Genet. 7:55-60.

Chani, E., V. Ashkenazi, J. Hillel, and E. Veilleux. 2002. Microsatellite marker analysis of an anther-derived potato family: Skewed segregation and gene-centromere mapping. Genome 45:236-242.

Claveria, E., J. Garcia-Mas, and R. Dolcet-Sanjuan. 2005. Optimization of cucumber doubled haploid line production using in vitro rescue of in vivo induced parthenogenic embryos. J. Amer. Soc. Hort. Sci. 130:555-560.

Cuny, F., R. Dumas de Vaulx, B. Longhi, and R. Siadous. 1992. Analyse des plantes de melon (Cucumis melo L.) issues de croisements avec du pollen irradié à différentes doses. Agronomie 12:623630.

Cuny, F., M. Grotte, R. Dumas de Vaulx, and A. Rieu. 1993. Effects of gamma irradiation of pollen on parthenogenetic haploid production in muskmelon (Cucumis melo L.). Environ. Exp. Bot. 33:301-312.

Danin-Poleg, Y., N. Reis, G. Tzuri, and N. Katzir. 2001. Development and characterization of microsatellite markers in Cucumis. Theor. Appl. Genet. 102:61-72.

Dhillon, N.P.S., R. Ranjana, K. Singh, I. Eduardo, A.J. Monforte, M. Pitrat, N.K. Dhillon, and P.P. Singh. 2007. Diversity among landraces of Indian snapmelon (Cucumis melo var. momordica). Genet. Resources Crop Evol. 54:1267-1283.

Dolcet-Sanjuan, R., E. Claveria, and A. Huerta. 1997. Androgenesis in Capsicum annuum L.-Effects of carbohydrate and carbon dioxide enrichment. J. Amer. Soc. Hort. Sci. 122:468-475.

Doyle, J.J. and J.L. Doyle. 1990. Isolation of plant DNA from fresh tissue. Focus 12:13-15.

Dryanovska, O.A. and I.N. Ilieva. 1983. In vitro anther and ovule culture in muskmelon (Cucumis melo L.). Comptes Rendus de l'Académie Bulgre des Sciences 36:1107-1110.

Dumas de Vaulx, R. 1979. Obtention de plantes haploïdes chez le melon (Cucumis melo L.) après pollinisation par Cucumis ficifolius A. Rich. Comptes Rendus de l'Académie des Sciences, Paris. Serie D 289:875-879.

Eduardo, I., P. Arús, and A.J. Monforte. 2005. Development of a genomic library of near isogenic lines (NILs) in melon (Cucumis melo L.) from the exotic accession PI 161375. Theor. Appl. Genet. 112:139-148.

Fazio, G., J.E. Staub, and S.M. Chung. 2002. Development and characterization of PCR markers in cucumber. J. Amer. Soc. Hort. Sci. 127:545-557.

Ficadenti, N., P. Veronese, S. Sestili, P. Crino, S. Lucretti, and M. Schiavi. 1995. Influence of genotype on the induction of haploidy in Cucumis melo L. by using irradiated pollen. J. Genet. Breed. 49:359364.

Foisset, N. and R. Delourme. 1996. Segregation distortion in androgenic plants, p. 189-201. In: Jain, S.M., S.K. Sopory, and R.E. Veilleux (eds.). In vitro haploid production in higher plants, Vol. 2. Kluwer Academic Publishers, Dordrecht, The Netherlands.

Foisset, N., R. Delourme, M.O. Lucas, and M. Renard. 1997. In vitro androgenesis and segregation distortion in Brassica napus L.: Spontaneous versus colchicine-doubled lines. Plant Cell Rep. $16: 464-468$.
Garcia-Mas, J., M. Oliver, H. Gómez-Paniagua, and M.C. de Vicente. 2000. Comparing AFLP, RAPD and RFLP markers for measuring genetic diversity in melon. Theor. Appl. Genet. 101:860-864.

Gémesné-Juhász, A., G. Venczel, and P. Balogh. 1997. Haploid plant induction in zucchini (Cucurbita pepo L. convar. giromontiina Duch) and in cucumber (Cucumis sativus L.) lines through in vitro gynogenesis. Acta Hort. 447:623-624.

Gonzalo, M.J., M. Oliver, J. Garcia-Mas, A. Monfort, R. DolcetSanjuan, N. Katzir, P. Arús, and A.J. Monforte. 2005. Simplesequence repeat markers used in merging linkage maps of melon (Cucumis melo L.). Theor. Appl. Genet. 110:802-811.

Graner, A., A. Jahoor, J. Schondelmaier, H. Siedler, K. Pillen, G. Fischbeck, G. Wenzel, and R.G. Herrmann. 1991. Construction of an RFLP map of barley. Theor. Appl. Genet. 83:250-256.

Guiderdoni, E. 1991. Gametic selection in anther culture of rice (Oryza sativa L.). Theor. Appl. Genet. 81:406-412.

Katzir, N., Y. Danin-Poleng, G. Tzuri, Z. Karchi, U. Lavi, and P.B. Cregan. 1996. Length polymorphism and homologies of microsatellites in several Cucurbitaceae species. Theor. Appl. Genet. 93: $1282-1290$.

Lim, W. and E.D. Earle. 2008. Effect of in vitro and in vivo colchicine treatments on pollen production and fruit recovery on melon plants obtained after pollination with irradiated pollen. Plant Cell Tissue Organ Cult. 95:115-124.

Lim, W. and E.D. Earle. 2009. Enhanced fruit set from parthenogenetic melon plants via colchicine treatment of nodal explants. Plant Cell Tissue Organ Cult. 98:351-356.

Lotfi, M., A.R. Alan, M.J. Henning, M.M. Jahn, and E.D. Earle. 2003. Production of haploid and double haploid plants of melon (Cucumis melo L.) for use in breeding for multiple virus resistance. Plant Cell Rep. 21:1121-1128.

Manninen, O.M. 2000. Associations between anther-culture response and molecular markers on chromosomes $2 \mathrm{H}, 3 \mathrm{H}$ and $4 \mathrm{H}$ of barley (Hordeum vulgare L.). Theor. Appl. Genet. 100:57-62.

Monforte, A.J., J. Garcia-Mas, and P. Arús. 2003. Genetic variability in melon based on microsatellite variation. Plant Breed. 122:153157.

Monforte, A.J., M. Oliver, M.J. Gonzalo, J.M. Alvarez, R. DolcetSanjuan, and P. Arús. 2004. Identification of quantitative trait loci involved in fruit quality traits in melon (Cucumis melo L.). Theor. Appl. Genet. 108:750-758.

Morrison, R.A. and D.A. Evans. 1988. Haploid plants from tissue culture: New plant varieties in shortened time frame. Bio/Technology 6:684-689.

Murigneux, A., D. Barloy, P. Leroy, and M. Beckert. 1993. Molecular and morphological evaluation of double haploid lines in maize. 1. Homogeneity within DH lines. Theor. Appl. Genet. 86:837-842.

Niemirowicz-Szczytt, K. and R. Dumas de Vaulx. 1989. Preliminary data of haploid cucumber (Cucumis sativus L.) induction. Cucurbit Genet. Coop. Rpt. 12:24-25.

Oliver, M., J. Garcia-Mas, M. Cardús, N. Pueyo, A.I. López-Sesé, M. Arroyo, H. Gómez-Paniagua, P. Arús, and M.C. deVicente. 2001. Construction of a reference linkage map for melon. Genome 44:836845.

Pauls, K.P. 1996. The utility of double haploid populations for studying the genetic control of traits determined by recessive alleles, p. 125-144. In: Jain, S.M., S.K. Sopory, and R.E. Veilleux (eds.). In vitro haploid production in higher plants, Vol. 1. Kluwer Academic Publishers, Dordrecht, The Netherlands.

Perin, C., L.S. Hagen, V. De Conto, N. Katzir, Y. Danin-Poleg, V. Portnoy, S. Baudracco-Arnas, J. Chadoeuf, C. Dogimont, and M. Pitrat. 2002. A reference map of Cucumis melo based on two recombinant inbred line populations. Theor. Appl. Genet. 104: 1017-1034.

Pitrat, M., P. Hanelt, and K. Hammer. 2000. Some comments on infraspecific classification of cultivars of melon. Acta Hort 510:2936. 
Przyborowski, J.A. 1996. Haploidy in cucumber (Cucumis sativus L.), p. 91-98. In: Jain, S.M., S.K. Sopory, and R.E. Veilleux (eds.). In vitro haploid production in higher plants. Vol. 3. Kluwer Academic Publishers, Dordrecht, The Netherlands.

Przyborowski, J.A. and K. Niemirowicz-Szczytt. 1994. Main factors affecting cucumber (Cucumis sativus L.) haploid embryo development and haploid plant characteristics. Plant Breed. 112:70-75.

Rivard, S.R., M. Cappadocia, G. Vincent, N. Brisson, and B.S. Landry. 1989. Restriction fragment length polymorphism (RFLP) analyses of plants produced by in vitro anther culture of Solanum chacoense Bitt. Theor. Appl. Genet. 78:49-56.

Sari, N., K. Abak, M. Pitrat, J.C. Rode, and R. Dumas de Vaulx. 1994. Induction of parthenogenetic haploid embryos after pollination by irradiated pollen in watermelon. HortScience 29:1189-1190.

Sauton, A. 1988a. Doubled haploid production in melon (Cucumis melo L.). Eucarpia Meeting on Cucurbits Breeding, AvignonMontfavet, France, 31 May to 2 June 1988. p. 119-128.

Sauton, A. 1988b. Effect of season and genotype on gynogenetic haploid production in muskmelon, Cucumis melo L. Sci. Hort. 35:71-75.

Sauton, A. 1989. Haploid gynogenesis in Cucumis sativus induced by irradiated pollen. Cucurbit Genet. Coop. Rpt. 12:22-23.

Sauton, A. and R. Dumas de Vaulx. 1987. Obtention de plantes haploïdes chez le melon (Cucumis melo L.) par gynogenèse induite par du pollen irradié. Agronomie 7:141-148.
Sestili, S. and N. Ficcadenti. 1996. Irradiated pollen for haploid production, p. 263-274. In: Jain, S.M., S.K. Sopory, and R.E. Veilleux (eds.). In vitro haploid production in higher plants, Vol. 1. Kluwer Academic Publishers, Dordrecht, The Netherlands.

Thompson, D.M., K. Chalmers, R. Waugh, B.P. Forster, W.T.B. Thomas, P.D.S. Caligari, and W. Powell. 1991. The inheritance of genetic markers in microspore-derived plants of barley Hordeum vulgare L. Theor. Appl. Genet. 81:487-492.

Van Berloo, R.V. 2008. GGT 2.0: Versatile software for visualization and analysis of genetic data. J. Hered. 99:232-236.

Van Ooijen, J.W. and R.E. Voorrips. 2001. JoinMap ${ }^{\circledR}$ version 3.0: Software for the calculation of genetic linkage maps. Plant Research Intl., Wageningen, The Netherlands.

Wang, Y.H., C.E. Thomas, and R.A. Dean. 1997. A genetic map of melon (Cucumis melo L.) based on amplified fragment length polymorphism (AFLP) markers. Theor. Appl. Genet. 95:791-798.

Yanmaz, R., S. Ellialtioglu, and K.Y. Taner. 1999. The effects of gamma irradiation on pollen viability and haploid plant formation in snake cucumber (Cucumis melo L. var. flexuosus Naud.). Acta Hort. 492:307-310.

Zivy, M., P. Devaux, J. Blaisonneau, R. Jean, and H. Thiellement. 1992. Segregation distortion and linkage studies in microsporederived double haploid lines of Hordeum vulgare L. Theor. Appl. Genet. 83:919-924. 